REVIEW

\title{
Methods for epidemiological study of injuries to professional football players: developing the UEFA model
}

\author{
M Hägglund, M Waldén, R Bahr, J Ekstrand
}

Br J Sports Med 2005;39:340-346. doi: 10.1136/bjsm.2005.018267

A problem with epidemiological studies of football injuries is the inconsistent manner in which injury is defined and data are collected. Projects have been initiated to study the incidence and causes of injury in football, but there is no uniformly accepted reporting system. In this report, some common piffalls encountered in the recording of injury are addressed, and practical guidelines for epidemiological studies are provided. An injury reporting system developed for the UEFA Football Safety Project for studies on professional footballers is used as a starting point for a general discussion on injury registration and compared with other existing reporting systems. The recording definition of injury may vary between studies depending on its purpose. A time loss injury definition is practical for all playing levels, and, as a minimum, results on time loss injuries should therefore always be reported separately to allow direct comparisons between studies. There is a need to agree on a uniform sports injury classification system with corresponding diagnostic criteria, as well as standardised return to play criteria after injury.

See end of article for authors' affiliations

Correspondence to: Professor Ekstrand, Department of Social Medicine and Public Health Science, Linköping University, Linköping, Sweden; jan.ekstrand@ telia.com

Accepted 17 March 2005
$\mathrm{T}$ he injury risk in professional football is high. A research group in the English Football Association (FA) evaluated the injury pattern and risk of injury in a series of studies of professional football in England. ${ }^{12}$ They showed that the overall risk was approximately 1000 times higher for professional players than for high risk industrial occupations.

The governing bodies for international football, FIFA (Federation of International Football Associations) and UEFA (Union of European Football Associations), as well as national football associations have expressed their concern about the demands placed on the modern footballer, and the translation of these physical and mental demands into injuries. ${ }^{3}$

Different research groups have initiated projects to study the incidence and causes of injury in football-for example, the FA group,,$^{14-7}$ the FIFA Medical Assessment and Research Center (F-MARC), ${ }^{8-10}$ and the Oslo Sports Trauma Research Center. ${ }^{11-15}$ Their ultimate goal is to prevent injuries and thereby improve the safety of the sport. Preventive measures are based on epidemiological research, and the first step in injury prevention is to establish the extent of the injury problem-the incidence, severity, and injury profile of the sport. ${ }^{16}$
One problem associated with epidemiological assessment of football injuries is the inconsistent manner in which injury is defined and data are collected and recorded. No consensus exists about study design, data collection, injury definition, and observation period. ${ }^{16-19}$ To interpret the results of an epidemiological study on football injuries, it is necessary to compare the results with data from other published studies. However, the methodological differences between studies may be greater than any statistically significant difference in the results. Meaningful comparisons of injury rates and injury patterns can only be made between studies using similar study designs, definitions, and data collection methods. ${ }^{3}$

In 1999, UEFA initiated a research project that aims to decrease the number of injuries and increase occupational safety for professional footballers. To begin with, the UEFA Medical Committee discussed the methodological design and system for injury reporting. Several sports injury reporting systems have been developed, ${ }^{20-23}$ but no system has been uniformly accepted. Sports injury surveillance systems should be sport specific. ${ }^{23}$ The aim of the discussions of the UEFA Medical Committee was to develop the optimum method for descriptive epidemiological studies on football at the professional level, and to develop a football specific injury reporting system.

The purpose of this review is to describe the development of the UEFA model and to provide practical guidelines for future studies based on existing sports injury surveillance systems and our experience using the UEFA model.

\section{THE UEFA FOOTBALL SAFETY RESEARCH PROJECT}

The development and validation of the study design and injury reporting system was carried out in three stages:

Stage 1: consensus discussions within the UEFA Medical Committee

In 1999 and 2000, discussions were held within the UEFA Medical Committee about optimal study design and reporting methodology. Parts of these discussions have been reported previously. ${ }^{3}$ The Medical Committee was able to reach an immediate consensus on some methodological aspects at the initial meetings: the study design, exposure registration, study period, and data collection forms. In other areas, an immediate consensus could not be reached, and a questionnaire was developed and used as a basis for further consensus discussions. A majority decision was used for questions for which consensus could not be reached. 


\section{Stage 2: pilot studies}

In January 2001, two pilot studies on the professional leagues in Sweden (full season) and Denmark (spring season) were started to test study design and data collection. Full reports of the results from these studies are presented elsewhere..$^{24}$

\section{Stage 3: approval of the design and forms by participating team doctors}

Before the start of the UEFA Champions League (UCL) study in July 2001, team doctors from the invited teams participated in a meeting in Nyon, Switzerland (UEFA headquarters), in May 2001. Here, the proposed methodological design, definitions, and reporting forms were discussed in detail based on experience from the first pilot studies, and these were approved after minor revision.

\section{PRACTICAL GUIDELINES FOR EPIDEMIOLOGICAL STUDIES OF FOOTBALL INJURIES: THE UEFA MODEL Study design}

Studies should have a prospective cohort design. This is because the retrospective design is associated with a well known risk of recall bias, as recently shown by the F-MARC group. ${ }^{9}$ Furthermore, a prospective cohort study is a more powerful study design than a case-control study when the purpose is to determine the risk factors for injury. ${ }^{26}$ Finally, with a prospective design, it is possible to measure accurately exposure to risk of injury.

\section{Exposure factor}

To evaluate the injury risk in a certain sport, the exposure factor needs to be considered - that is, the time during which the participant is at risk of injury should be measured.$^{27}$ On the basis of an accurate exposure record, injury incidence can be expressed, usually as the number of injuries per 1000 hours of participation. ${ }^{16}$ Ideally, the exposure record should be individual and based on real exposure time, rather than on an estimate based on attendance during training sessions and matches. If individual exposure is recorded, a more advanced model can be used to study risk factors for injury: a Cox proportional hazards regression model. Exposure time, measured as the number of hours of exposure for each player (training and match participation), from the start of the follow up period (the start of the season) until the event (the first injury) or the end of follow up (for players who are not injured) is the main variable here. The strength of this approach is that the method can be adjusted for the fact that playing time can vary greatly between players in a team. This may be important, because the best players play more games than the substitutes, and perhaps even train harder. It also takes censorship into account-that is, shortened follow up for reasons other than injury, such as sickness, moving to a different club, quitting the sport for reasons other than injury.

\section{Study period}

Injury risk and pattern vary over the football season, ${ }^{528-30}$ which is why the study period should include the entire season, or several seasons, including both the preseason and the competitive season.

\section{Data collection forms}

Basically, three different forms are required for the collection of data in a study of injury risk in sports. ${ }^{23}$

\section{Baseline form}

Firstly, a baseline form on which at least anthropometric data and previous medical history are noted. The baseline form developed for the UEFA studies includes information about player age, weight, height, dominant leg (kicking leg), and history of previous major injuries and operations. The form is also used to obtain informed consent. Depending on the purpose of the study, the form can be expanded to include other variables from the preseason evaluation of potential risk factors-for example, training background, playing experience, goniometric measurements, joint laxity measurements, the results of fitness tests, player positions. As a medical history based on information from the player may be confounded by recall bias, it is recommended that players are provided with a copy of their club medical records before being transferred to another club. It may even be possible to develop standard forms for this purpose.

\section{Exposure registration form}

Secondly, a form is required on which attendance and individual exposure is recorded. This can be a weekly or monthly form of attendance, and it should cover all training sessions and matches for the players included. The basic attendance record developed for the UEFA studies includes a list of players' names and code numbers, and a column for each training session and match in which individual participation is recorded in minutes. The attendance record can also be modified to suit the purposes of the study-for example, the addition of weather conditions, playing surface (grass versus artificial turf), or information on training content (strength training, ball training, etc).

\section{Injury form}

Thirdly, information about injuries should be recorded on a standard injury report form. This should at least include information about the date of injury, whether the injury occurred during training or match play, the injury type, location, and a measure of injury severity. As the initial diagnosis may later be revised after radiographic scrutiny or further consultation, it should be stressed to those collecting data that this new information must be added to the injury form. For the UEFA studies, it was decided that the injury form should be restricted to one page and only a few questions. Information about the type and circumstances of injury are recorded in tabular form. Depending on the purpose of the study, specific information can be added to the injury form-for example, contact or non-contact injury, injury mechanisms, playing surface, weather conditions. As a rule, to enable assessment of the effect of a factor on injury risk, data related to this factor must to be recorded on the injury form and on the exposure form.

\section{Ethics}

Individual written informed consent should be obtained from all participating players in accordance with the Declaration of Helsinki, and studies should be externally reviewed by an appropriate ethics committee.

\section{Study manual}

A concern with epidemiological studies in which many observers are involved is to ensure that data are collected in a consistent fashion. An instruction manual was therefore created for the UEFA studies, and distributed to the clubs before the start of the study. Such a manual should describe the various definitions used in the study in detail. It should also give examples of how to fill in the various forms and, especially, include fictive cases that represent different scenarios where it might be difficult to know how to complete the forms.

\section{Who should be the contact person in the club?}

Each club should select a contact person responsible for completing and sending in the study forms to the research staff. To be able to accurately record individual exposure in the UEFA studies, a criterion for filling in the attendance record (exposure form) was that the person responsible 
should be available at all training sessions and matches. It was decided that ideally a member of the medical team (team doctor or physiotherapist) should be responsible for filling in the forms and forward them to the research staff. However, in clubs where the medical team does not attend all practice sessions or matches, different solutions should be soughtfor example, an assistant coach or equipment manager. It should be clearly stated who was the prime observer in a study as differences in data collection methods may interfere with comparisons between studies.

What should be the inclusion and exclusion criteria? Previous studies conducted at amateur and semiprofessional levels have included a fixed number of players in each team-for example, the "top" 15 or 18 players in the team. ${ }^{12} 3132$ However, at the professional level, the number of contracted players is higher. It was argued that the exclusion of a number of players in a team might introduce selection bias. Therefore it was decided that all players with a first team contract should be included. This approach has also been used in other recent studies. ${ }^{11}$

In some studies, players with an existing injury or a history of a serious injury - for example, mechanical instability of the knee joint-have been excluded. ${ }^{33}$ This would introduce a potential bias, both related to the overall estimate of injury risk and to any estimations of risk factor performed. It was therefore decided that players with a previous injury should not be excluded. Players with an existing injury at the start of the study should also be included, but that particular injury would not be included in the injury statistics, and the exposure not included until the player is fully cleared for all activities.

\section{Definition of injury}

To allow comparison between different studies, injuries have to be defined in a similar way. ${ }^{36}{ }^{18}$ Most studies of football injuries have used a "time loss" definition of injury, meaning that a recordable injury is one that causes absence from football participation. ${ }^{12} 12132829313234-39$ Other definitions of injury require that the player needs medical treatment for the injury ("medical assistance" definition), ${ }^{40-42}$ or that an injury is recorded regardless of whether or not it causes subsequent absence from training or match play ("tissue injury" definition)..$^{1020}$ Some studies have used a combination of the above definitions. ${ }^{43-46}$

Some authors have recommended the use of the tissue injury definition, ${ }^{9}{ }^{19}$ partly because of the subjective components of the time loss definition. A tissue injury diagnosis may be the most objective method to determine whether an injury has occurred. However, a truly objective tissue injury definition is seldom used because specific objective criteriafor example, examination with magnetic resonance imaging, ultrasound, etc-have to be included and these are usually costly and not always practical. If objective examinations are not carried out, an observer and patient bias is introduced. The observer is subjective in his/her judgment of a tissue injury, and the player is subjective in his response to the examination.

A medical attention definition was not believed to be the most suitable as this would include many minor injuries and incidents that are not significant for the overall injury risk. Moreover, using a medical attention definition could introduce a bias between teams where medical attention is easily available, such as in the major European football leagues, and teams that have no team doctor and where the physiotherapist only attends some training sessions and not even all matches. ${ }^{12}$ It is likely that the reporting threshold would be substantially higher in the latter case, leading to an apparently lower injury incidence.
For the UEFA studies, it was decided that the time loss definition of injury was suitable for studies at the professional level. Although this definition depends on the frequency of training sessions and matches, the teams at the professional level usually train or compete daily, which minimises the risk of missing less severe injuries. Furthermore, it can be argued that injuries resulting in time lost from training and matches have a substantial impact on the player's health and performance, ${ }^{17}$ and also on the performance of the club, and therefore should be recorded.

In the pilot study on the Swedish professional league, we compared a time loss injury definition, as defined by Ekstrand, ${ }^{47}$ with a tissue injury definition, as defined by Junge and Dvorak, ${ }^{9}$ and found no difference in injury incidence when using these definitions. ${ }^{25}$ Thus, at elite levels the difference between a time loss and a tissue injury definition may be minimal. However, it should be noted that at lower levels, teams have fewer training sessions and matches, and this increases the risk of missing less severe injuries with only one or two days absence. On the other hand, as access to medical expertise is usually also limited at lower levels, the recording of injuries accurately based on a tissue injury definition could also be hampered.

The definition of a time loss injury varies in the literature. Different reports have defined injury as: causing absence from the next training session or match after the event, ${ }^{29313236-38}$ being unable to participate in a match or training session because of an injury, ${ }^{12} 35$ causing absence from training and matches for at least one day, ${ }^{13}$ two days ${ }^{2} 28$ or one week after an incident. ${ }^{39}$ Clearly, an agreement on a uniform time loss injury definition is needed. The injury definition agreed on by the UEFA Medical Committee was a time loss definition previously used by Ekstrand ${ }^{47}$ : an injury that occurred during a scheduled training session or match that caused absence from the next training session or match. It may also be appropriate to include injuries that cause the player to interrupt a training session or match, regardless of whether the player misses the next training session or match. This is especially important at lower levels, where training and matches are less frequent. These injuries could then be reported in a separate category as "zero day" time loss injuries.

Care should also be taken to distinguish between the recording definition and the reporting definition. Even in a study where injuries are recorded using a medical attention or tissue injury definition, in the final report it is critical that, as a minimum, the number of injuries that cause time loss, as well as the corresponding time loss injury incidence are reported separately, not only the incidence of medical attention injuries or injuries causing tissue damage. This would then allow subsequent comparison between this study and others using a time loss definition.

\section{Injury severity}

When using a time loss injury definition it is important to take injury severity into consideration, ${ }^{16}$ and this is usually described according to the number of days of absence from participation. $^{12} 12293034373948$ The cut-off point for different categories of injury severity differs between studies. ${ }^{9}$ According to the UEFA consensus discussions, injury severity was initially categorised as minor (1-7 days absence), moderate (8-28 days), and major ( $>28$ days). The first group was later split into two categories (slight (1-3 days absence) and minor (4-7 days)) to facilitate comparisons with the studies of the FA group. ${ }^{12}$ The severity should be based on real time loss from participation (calculated from the attendance record) and not from an estimated absence period. 


\section{Classification of injury type}

A prerequisite for comparison of injury patterns between studies is that different types of injuries are clearly distinguished and defined in a similar way by different researchers, as well as different observers. Commonly, authors distinguish between injuries that result from overuse and those that result from trauma (acute injuries), although definitions vary greatly. ${ }^{9}$ In the UEFA studies, injury types were divided into seven different categories (table 1). A similar approach has been used in other studies. ${ }^{11} 1838$

\section{How should injuries during non-football activities be accounted for?}

Only injuries occurring during scheduled team activities should be included in the statistics. Injuries that occur during leisure time or from participating in other sports (outside team training) and absence as a result thereof should not be counted, as the purpose is to evaluate the risk of injury for professional footballers and not the overall risk of injury including other activities. However, team activities are not usually limited to football training and matches, but also include various forms of fitness training (strength building, running, etc). To describe the true risk of injury to a professional footballer, the injuries and exposure to activities other than football should also be recorded. However, these should be reported separately from football training and matches.

\section{What is a reinjury?}

A reinjury is usually defined as an injury occurring after an initial injury of the same type and location. We debated whether a specific time period should be included in the definition-for instance, an identical injury within the same season-or whether no time limit should be adopted. The decision was that a reinjury should be defined as an injury of the same type and location of a previous injury that occurred within two months of the final rehabilitation day of the previous injury.

It could be argued that injuries may cause deficits in proprioception and structural damage, such as scar tissue in muscles, that may still be present more than two months after the initial injury. This idea is supported by studies that have shown that previous injury is a strong risk factor for a new identical injury during a season. ${ }^{12}$ Other injuries never heal completely and may carry an increased risk of reinjury regardless of time, such as a reconstructed anterior cruciate ligament injury, or after a partial meniscectomy. However, a time limit of two months was chosen to avoid recall bias for injuries that had occurred before the start of the study. It was argued that recall bias might interfere when using a reinjury definition such as having ever had a previous injury during a career or during a preceding season. At the professional level, most teams keep accurate medical records, and it might be

\begin{tabular}{cl} 
Table 1 & Classification of different injury types \\
\hline $\begin{array}{c}\text { Traumatic } \\
\text { Sprain } \\
\text { Strain } \\
\text { Contusion }\end{array}$ & $\begin{array}{l}\text { Acute distraction injury of ligaments or joint capsules } \\
\text { Acute distraction injury of muscles and tendons } \\
\text { Tissue bruise without concomitant injuries classified } \\
\text { elsewhere }\end{array}$ \\
$\begin{array}{l}\text { Fracture } \\
\text { Dislocationatic break of bone }\end{array}$ & $\begin{array}{l}\text { Partial or complete displacement of the bony parts of a } \\
\text { joint } \\
\text { Injuries not classified elsewhere. Examples: wound, } \\
\text { Other }\end{array}$ \\
$\begin{array}{l}\text { concussion, etc } \\
\text { Overuse pain syndrome of the musculoskeletal system with } \\
\text { insidious onset and without any known trauma or disease } \\
\text { that might have given previous symptoms (modified from } \\
\text { Orava }{ }^{\text {s6 }} \text { ) }\end{array}$ \\
\hline
\end{tabular}

possible to accurately trace injuries several seasons back. However, these records may not be as precise for players transferred from lower level teams.

\section{Participation: when is a player considered fully rehabilitated after an injury?}

Even a time loss definition such as that used by UEFA leaves some room for interpretation. The question is when should a player be classified as having returned to activity, as this determines the injury severity and reinjury rate. Is this when he begins taking part in organised training, perhaps warming up with the team, but is not yet ready to take part in all team activities? In principle, return to sport should imply that the player is considered fully rehabilitated after an injury.

According to the UEFA model, it was decided that a player should be able to take part in $100 \%$ of the team's training programme to be recorded as participating in that session. If a player participates in a part of the training session only, then this player should be regarded as injured. Árnason et a ${ }^{35}$ have suggested that the player is defined as injured until he is able to play a match or comply fully with all instructions given by the coach, including sprinting, turning, shooting, and playing football at full tempo. At the professional level, the team medical staff normally decides when the player is able to return to football. Thus, a player is considered injured until he is given clearance by the medical staff to participate fully in team training and match play. ${ }^{28}$ Likewise, if a player participates in a modified training programme to avoid aggravating an incipient pain syndrome, this player should also be recorded as injured.

The decision as to when a player is considered fully rehabilitated is still subjective, and standard return to play criteria would facilitate comparison between studies or between different subgroups (different teams, geographical locations, etc) within the study population. A suitable criterion could be that players should reach various preseason physical parameters or functional score values before being allowed back to play. To date, no such tests have been properly evaluated.

\section{Major injuries: what about players who sustain an end of season injury?}

A player who sustains an end of season injury should preferably be followed until the final rehabilitation date. If this is not possible-for example, the player is transferred to another club-the team medical staff should provide an estimated date of return to full team training and match play on the injury card.

\section{What about players leaving the club during the season?}

As mentioned above, players may leave the club during the season-for example, they may be transferred to another club or leave because of illness. These players should be censored when leaving the club, but their exposure and injury data should be included until the day they leave the team. If a player is injured when he leaves the club, the subsequent absence should be followed up for information of the date of return to full football activity.

\section{What is the definition of a training session?}

A training session was defined as: a coach directed physical activity carried out with the team. A recovery session with pool training after a match and a strength session in the gym should thus be recorded as training sessions, whereas a theoretical session-for example, video, team meetingshould not be recorded. Individual training sessions should not be included in the definition of a recordable training session because these are hard to standardise and it would be difficult to register individual sessions accurately. 
What is already known on this topic

- No methodological consensus exists for epidemiological studies of sports injuries.

- Owing to variations in study design, definition of injury, and data collection methods, it is difficult to compare the results between studies.

\section{Training and matches for national teams}

At the professional level, many teams have players who participate in national team activities and matches. It was decided that exposure and injuries that resulted from national team participation should be recorded for the players involved. The risk of overexertion is a major concern at the highest professional level, ${ }^{49}$ and it is essential to include national team appearances to be able to study the training and match load in relation to injury risk of the individual player in each team.

One problem is to ensure that accurate exposure and injury information is being collected during participation in national team play. Injury surveillance systems have been successfully implemented at the national team level in FIFA tournaments, ${ }^{20}{ }^{41}$ and similar work is being carried out by UEFA during European tournaments. However, there are only a few reports that include data on appearances outside major tournaments. ${ }^{14} 3650$ Standard recording of exposure and injury data during all national team gatherings, including friendly appearances and training camps, is necessary to present an accurate picture of injury risk and pattern at the highest professional level.

\section{Training and matches with reserve teams or youth teams}

Likewise, it was decided that exposure and injuries for first team players who participate with reserve teams or youth teams should also be recorded. However, if a first team player participates in a training session or match with the reserve team as a part of rehabilitation after an injury, this should not be recorded as training or match attendance. Instead, he should be recorded as injured until he has been given clearance from the medical staff to participate fully in team

Table 2 Checklist for epidemiological studies of football injuries: the UEFA model

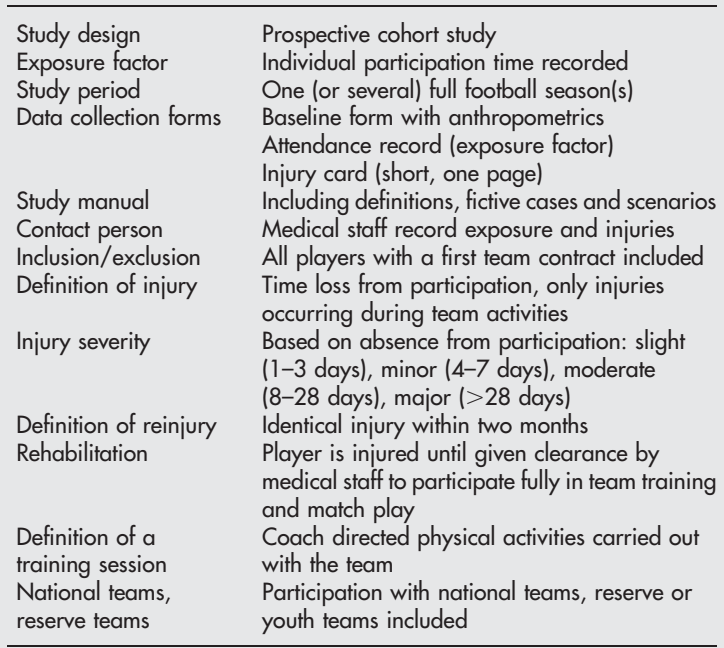

What this study adds

- Common piffalls encountered in epidemiological studies on football injuries are discussed.

- Practical guidelines and a methodological checklist that may serve as the standard for studies on footballers at the professional level are provided.

training and match play with the first team, as described above.

Table 2 shows a suggested checklist for epidemiological studies of football injuries.

\section{FUTURE CONSIDERATIONS}

\section{Basic forms valuable in the first step towards injury prevention}

The aim of the first part of the study was to investigate the extent of the injury problem-that is, the first step in the sequence of injury prevention. ${ }^{16}$ To this end the basic data collection forms have functioned well. Registration of individual injuries and exposures has allowed evaluation of injury patterns and severity, as well as the assessment of injury risk based on real exposure time. ${ }^{24} 25495152$ However, as mentioned above, depending on the purposes of future studies, additional variables may be added to the basic forms in order to study the relation between potential internal and external risk factors and injuries.

\section{Is the data collection reliable?}

As mentioned, a concern with data being collected from several teams is the many different observers involved in recording attendance and injury data. By providing the teams with a study instruction manual, the reliability of data recording can be assumed to be improved. However, the reliability of the data collection forms used in the UEFA model for professional football, as well as other reporting systems, needs to be evaluated in the future. Only a few studies have documented the validity and reliability of injury registration methods in sports. ${ }^{22} 23$

\section{Uniform diagnosis criteria are required}

A challenge for future injury registration studies is to agree on a uniform list of diagnosis codes, as well as corresponding diagnostic criteria. This would facilitate comparisons between studies and between different risk groups-for example, different age groups, different teams. Examples of such diagnosis code lists are the Orchard Sports Injury Classification System (OSICS), ${ }^{53}$ which has been used in some recent studies by the Oslo group, ${ }^{1322}$ and the F-MARC injury reporting system developed for major tournaments. ${ }^{20}$ Another more familiar example is the International Classification of Diseases (ICD-10) diagnosis code list, which some would argue is limited by the lack of specific codes for common sports medicine conditions.

\section{Computer and web based recording systems}

New computer and web based recording systems have been introduced into sports injury epidemiology. ${ }^{23} 5455$ One benefit of a web based system is that an accurate medical history can be retrieved for players transferred between clubs, thus reducing the risk of recall bias that is often present in self reporting of previous injuries. Another obvious benefit of such reporting systems is that it makes data collection easier and less time consuming for the researcher. It simplifies, for example, data analysis in that researchers do not have to computerise data from paper forms for data analysis. However, it is vital that the collection of data is performed 
in a similarly strict fashion, and that data are controlled with the same scrutiny, as with a paper reporting system. The system must allow the researcher to check reports continuously during the study period to ensure complete and accurate reporting. A web or computer based system may in fact increase the reliability and completeness of reporting as the system can be programmed to check for logical errors or missing data at the time of entry. It can be programmed, for example, to disallow an entry of a lateral ligament injury as an overuse injury, or prevent the recorder from entering an injury form without a specific diagnosis. It can also monitor reporting, sending automated reminders to the data collectors if they are late in reporting exposure data.

One issue that must be considered when developing a computer or web based system to collect injuries from several locations is patient confidentiality. Many countries have introduced legislation clearly outlining the security requirements for the electronic storage and transfer of medical information. Care must be taken at all levels to ensure that injury information cannot be traced by outsiders, and this is especially important with the high profile elite athlete.

\section{ACKNOWLEDGEMENTS}

We appreciate the support and cooperation of UEFA, especially its President Lennart Johansson, Technical Director Andy Roxburgh, the Chairman of the Medical Committee of FIFA Dr Michel D'Hooghe, the UEFA Manager of Medical Matters Andrea Freely, the members of the UEFA Medical Committee: Dr Urs Vogel (Switzerland), Dr Mogens Kreutzfeldt (Denmark), Professor Mehmet S Binnet (Turkey), Professor W Stewart Hillis (Scotland), Professor Lamberto Perugia (Italy), Dr Enrique Gonzalez Ruano (Spain), Dr Jacques Lienard (France), and Dr Gunnar Männik (Estonia). We would also like to express our gratitude to all the team doctors in the Champions League teams for their participation in the consensus discussions. The assistance of Dr Peter Cox in language correction is greatly appreciated. Finally, we gratefully acknowledge UEFA, the Swedish Football Association, and the Swedish Sports Confederation (Sports Research Council) for financial support of this study.

\section{Authors' affiliations \\ M Hägglund, M Waldén, J Ekstrand, Department of Social Medicine and Public Health Science, Linköping University, Linköping, Sweden R Bahr, Norwegian University of Sport \& Physical Education, Oslo, Norway}

Competing interests: none declared

\section{REFERENCES}

1 Hawkins RD, Fuller CW. A prospective epidemiological study of injuries in four English professional football clubs. Br J Sports Med 1999;33:196-203.

2 Hawkins RD, Hulse MA, Wilkinson C, et al. The association football medical research programme: an audit of injuries in professional football. $\mathrm{Br} J$ Sports Med 2001;35:43-7.

3 Ekstrand J, Karlsson J. The risk for injury in football. There is a need for a consensus about definition of injury and the design of studies. Scand J Med Sci Sports 2003;13:147-9.

4 Drawer S, Fuller CW. Evaluating the level of injury in english professional football using a risk based assessment process. Br J Sports Med 2002;36:446-51.

5 Woods C, Hawkins R, Hulse M, et al. The Football Association Medical Research Programme: an audit of injuries in professional football: analysis of preseason injuries. Br J Sports Med 2002;36:436-41.

6 Woods C, Hawkins RD, Maltby S, et al. The Football Association Medical Research Programme: an audit of injuries in professional football: analysis of hamstring injuries. Br J Sports Med 2004;38:36-41.

7 Woods C, Hawkins R, Hulse M, et al. The Football Association Medical Research Programme: an audit of injuries in professional football: an analysis of ankle sprains. Br J Sports Med 2003;37:233-8.

8 Dvorak J, Junge A, Chomiak J, et al. Risk factor analysis for injuries in football players. Possibilities for a prevention program. Am J Sports Med 2000;28(suppl 5):S69-74

9 Junge A, Dvorak J. Influence of definition and data collection on the incidence of injuries in football. Am J Sports Med 2000;28(suppl 5):S40-6.

10 Peterson L, Junge A, Chomiak J, et al. Incidence of football injuries and complaints in different age groups and skill-level groups. Am J Sports Med 2000;28(suppl 5):S51-7.
11 Andersen TE, Tenga A, Engebretsen L, et al. Video analysis of injuries and incidents in Norwegian professional football. Br J Sports Med 2004;38:626-31

12 Árnason Á, Sigurdsson SB, Gudmundsson Á, et al. Risk factors for injuries in football. Am J Sports Med 2004;32(suppl 1):S5-16.

13 Andersen TE, Floerenes TW, Árnason A, et al. Video analysis of the mechanisms for ankle injuries in football. Am J Sports Med 2004;32(suppl 1):S69-79.

14 Andersen TE, Larsen O, Tenga A, et al. Football incident analysis: a new video based method to describe injury mechanisms in professional football. Br J Sports Med 2003;37:226-32.

15 Árnason Á, Sigurdsson SB, Gudmundsson Á, et al. Physical fitness, injuries, and team performance in soccer. Med Sci Sports Exerc 2004;36:278-85

16 Mechelen Wv, Hlobil H, Kemper H. Incidence, severity, aetiology and prevention of sports injuries. Sports Med 1992;14:82-99.

17 Keller CS, Noyes FR, Buncher CR. The medical aspects of soccer injury epidemiology. Am J Sports Med 1987; 15:230-7.

18 Inklaar H. Soccer injuries. I: Incidence and severity, Sports Med 1994;18:55-73.

19 Dvorak J, Junge A. Football injuries and physical symptoms. A review of the literature. Am J Sports Med 2000;28(suppl 5):S3-9.

20 Junge A, Dvorak J, Graf-Baumann T, et al. Football injuries during FIFA tournaments and the Olympic Games, 1998-2001: development and implementation of an injury-reporting system. Am J Sports Med 2004;32(suppl 1):S80-9.

21 Levy $M$. Formulation and sense of the NAIRS athletic injury surveillance system. Am J Sports Med 1988;16(suppl 1):S132-3.

22 McManus A. Validation of an instrument for injury data collection in rugby union. Br J Sports Med 2000;34:342-7.

23 Meeuwisse WH, Love EJ. Development, implementation, and validation of the Canadian Intercollegiate Sport Injury Registry. Clin J Sport Med 1998:8:164-77.

24 Hägglund $M$, Waldén $M$, Ekstrand J. Injury incidence and distribution in elite football: a prospective study of the Danish and the Swedish top divisions. Scand J Med Sci Sports 2005;15:21-8.

25 Waldén M, Hägglund M, Ekstrand J. Injuries in Swedish elite football: a prospective study on injury definitions, risk for injury and injury pattern during 2001. Scand J Med Sci Sports 2005; 15:118-25.

26 Bahr R, Holme I. Risk factors for sports injuries: a methodological approach. Br J Sports Med 2003:37:384-92.

27 de Loës M. Exposure data. Why are they needed? Sports Med 1997;24:172-5.

28 Lewin G. The incidence of injury in an English professional soccer club during one competetive season. Physiotherapy 1989;75:601-5.

29 Engström B, Forssblad M, Johansson C, et al. Does a major knee injury definitely sideline an elite soccer player? Am J Sports Med 1990;18:101-5.

30 Ekstrand J, Gillquist J. Soccer injuries and their mechanisms: a prospective study. Med Sci Sports Exerc 1983;15:267-70.

31 Ekstrand J, Gillquist J, Möller $M$, et al. Incidence of soccer injuries and their relation to training and team success. Am J Sports Med 1983;1 1:63-7.

32 Ekstrand J, Tropp H. The incidence of ankle sprains in soccer. Foot Ankle 1990;11:41-4.

33 Ekstrand J, Gillquist J, Liljedahl SO. Prevention of soccer injuries. Supervision by doctor and physiotherapist. Am J Sports Med 1983;11:116-20.

34 Lüthje P, Nurmi I, Kataja M, et al. Epidemiology and traumatology of injuries in elite soccer: a prospective study in Finland. Scand J Med Sci Sports 1996;6:180-5

35 Árnason Á, Gudmundsson Á, Dahl HA, et al. Soccer injuries in Iceland. Scand J Med Sci Sports 1996;6:40-5.

36 Ekstrand J, Waldén $M$, Hägglund $M$. Risk for injury when playing in a national football team. Scand J Med Sci Sports 2004;14:34-8.

37 Nielsen AB, Yde J. Epidemiology and traumatology of injuries in soccer. Am J Sports Med 1989;17:803-7.

38 Poulsen TD, Freund KG, Madsen F, et al. Injuries in high-skilled and lowskilled soccer: a prospective study. Br J Sports Med 1991;25:151-3.

39 Junge A, Chomiak J, Dvorak J. Incidence of football injuries in youth players. Comparison of players from two European regions. Am J Sports Med 2000;28(suppl 5):S47-50.

40 Fuller CW, Smith GL, Junge A, et al. An assessment of player error as an injury causation factor in international football. Am J Sports Med 2004;32(suppl 1):S28-35.

41 Junge A, Dvorak J, Graf-Baumann T. Football injuries during the World Cup 2002. Am J Sports Med 2004;32(suppl 1):S23-7.

42 Morgan BE, Oberlander MA. An examination of injuries in major league soccer. The inaugural season. Am J Sports Med 2001;29:426-30.

43 Hawkins RD, Fuller CW. Risk assessment in professional football: an examination of accidents and incidents in the 1994 World Cup finals. Br J Sports Med 1996;30:165-70.

44 Hawkins RD, Fuller CW. An examination of the frequency and severity of injuries and incidents at three levels of professional football. Br J Sports Med 1998;32:326-32.

45 Junge $A$, Rosch D, Peterson L, et al. Prevention of soccer injuries: a prospective intervention study in youth amateur players. Am J Sports Med 2002;30:652-9.

46 Lindenfeld TN, Schmitt DJ, Hendy MP, et al. Incidence of injury in indoor soccer. Am J Sports Med 1994;22:364-71.

47 Ekstrand J. Soccer injuries and their prevention. Linköping: Department of Surgery, Linköping University, 1982. 
48 Andersen TE, Engebretsen L, Bahr R. Rule violations as a cause of injuries in male Norwegian professional football: are the referees doing their job? Am J Sports Med 2004;32(suppl 1):S62-8.

49 Ekstrand J, Waldén $M$, Hägglund $M$. A congested football calendar and the wellbeing of players: correlation between match exposure of European footballers before the World Cup 2002 and their injuries and performances during that World Cup. Br J Sports Med 2004;38:493-7.

50 Wekesa, M. A one year prospective study of soccer injuries in the 1992-1993 Kenyan national team. Afr J Health Sci 1995;2:392-4.

51 Hägglund M, Waldén $M$, Ekstrand J. Exposure and injury risk in Swedish elite football: a comparison between seasons 1982 and 2001. Scand J Med Sci Sports 2003; 13:364-70
52 Waldén $M$, Hägglund $M$, Ekstrand J. UEFA Champions League study: a prospective study of injuries in professional football during the 2001-2002 season. Br J Sports Med, 2005; in press.

53 Orchard J. Orchard Sports Injury Classification System (OSICS). Sports Health 1993;11:39-41.

54 National Collegiate Athletic Association. Injury surveillance system. Washington: NCAA, 2002.

55 Injury Tracker. http://www.injurytracker.com.

56 Orava S. Exertion injuries due to sports and physical exercise. A clinical and statistical study of nontraumatic overuse injuries of the musculoskeletal system of athletes and keep-fit athletes. Thesis: University of Oulu, Finland, 1980.

\section{ELECTRONIC PAGES}

\section{Online case and short reports}

7 he following electronic only articles are published in conjunction with this issue of BJSM

\section{Case presentation: a novel way of treating acute cauliflower ear in a professional rugby player D J M Macdonald, N Calder, G Perrett, et al} Acute auricular haematoma is a common problem in rugby players and can be difficult to treat due to re-accumulation of the fluid and can subsequently cause the unsightly cauliflower ear. We present a case of auricular haematoma affecting the central part of the pinna in a professional rugby player. This was treated successfully by aspiration and the use of silicone splints which allowed the player to continue training and competing.

(Br J Sports Med 2005;39:e29) http://bjsm.bmjjournals.com/ cgi/content/full/39/6/e29

\section{The exercise addiction inventory: a quick and easy screening tool for health practitioners \\ M D Griffiths, A Szabo, A Terry}

Background: Exercise addiction is not routinely screened for probably because available instruments take a long time to administer, their scoring may be complicated, and their interpretation is not always obvious. A new psychometric instrument has been developed that is capable of identifying people affected by, or at risk of, exercise addiction: the exercise addiction inventory (EAI). A preliminary report showed the EAI had good reliability and validity.
Objectives: To test further the EAI's psychometric properties and show that it would be quick and simple to administer by general practitioners.

Methods: A sample of 200 habitual exercisers were given the EAI and two existing exercise addiction scales (obligatory exercise questionnaire; exercise dependence scale). Two weeks later, another sample of 79 exercisers were administered the EAI to determine the test-retest reliability of the questionnaire.

Results: The original data from the preliminary report were reanalysed to determine the split half correlation of the EAI.

This was found to be 0.84 (Guttman split-half coefficient). A correlation between weekly frequency of exercising and EAI scores was also determined, and it was found that the two variables shared $29 \%$ of the variance $\left(r^{2}=0.29\right)$. The test-retest reliability of the scale was found to be very good (0.85).

Conclusions: The EAI is a valid and reliable tool which would be capable of helping general practitioners to quickly and easily identify people affected by, or at risk of, exercise addiction.

(Br J Sports Med 2005;39:e30) http://bjsm.bmjjournals.com/ cgi/content/full/39/6/e30 